\title{
Non-natural Nucleosides
}

\section{Synthesis and Antiviral Properties of Spirocyclic $[1,2,3]-$ Triazolooxazine Nucleosides}

\author{
Antonio Dell'Isola, ${ }^{[a]}$ Matthew M. W. McLachlan, ${ }^{[b]}$ Benjamin W. Neuman, ${ }^{[c]}$ Hawaa M. N. Al- \\ Mullah, ${ }^{[c]}$ Alexander W. D. Binks, ${ }^{[c]}$ Warren Elvidge, ${ }^{[c]}$ Kenneth Shankland, ${ }^{[a]}$ and \\ Alexander J. A. Cobb*[a]
}

\begin{abstract}
An efficient synthesis of spirocyclic triazolooxazine nucleosides is described. This was achieved by the conversion of $\beta$-D-psicofuranose to the corresponding azido-derivative, followed by alkylation of the primary alcohol with a range of propargyl bromides, obtained by Sonogashira chemistry. The products of these reactions underwent 1,3-dipolar addition smoothly to generate the protected spirocyclic adducts. These were easily deprotected to give the corresponding ribose nucleosides. The library of compounds obtained was investigated for its antiviral activity using MHV (mouse hepatitis virus) as a model wherein derivative $\mathbf{3} \mathbf{f}$ showed the most promising activity and tolerability.
\end{abstract}

The design and synthesis of nucleoside analogues has been a subject of great interest in the discovery of novel anticancer and antiviral agents owing to the fact that they can be involved in the disruption of nucleic acid biosynthesis and thus inhibit cellular division and viral replication. ${ }^{[1]}$ Additionally, they have been utilised for various gene-silencing techniques as constituents of antisense oligonucleotides, small interfering RNAs (siRNAs) and microRNA-targeting oligonucleotides (antimiRNAs). ${ }^{[2]}$

In particular, conformationally restricted nucleosides such as "locked nucleic acids" (LNAs), whereby the sugar moiety of the nucleoside is locked in the bioactive $\mathrm{C3}^{\prime}$-endo (North) or C2'endo (South) conformations, represent an interesting class of nucleoside inhibitor as they can show a dramatic improvement in enzymatic recognition, as well as enhancing base stacking and backbone pre-organisation. ${ }^{[3]}$ Most of these systems are locked by virtue of bridging groups on the furanose unit

[a] A. Dell'Isola, Dr. K. Shankland, Dr. A. J. A. Cobb

School of Chemistry, Food and Pharmacy (SCFP)

University of Reading, Whiteknights, Reading, Berks RG6 6AD (UK)

E-mail:a.j.a.cobb@reading.ac.uk

[b] Dr. M. M. W. McLachlan

Syngenta, Jealott's Hill International Research Centre Bracknell, Berks RG42 6EY (UK)

[c] Dr. B. W. Neuman, H. M. N. Al-Mullah, A. W. D. Binks, W. Elvidge School of Biological Sciences, University of Reading Whiteknights, Reading, Berks RG6 6AJ (UK)

Supporting information for this article is available on the WWW under http://dx.doi.org/10.1002/chem.201403560. alone, but there are also examples whereby the nucleobase is directly involved in the conformational restriction of the nucleoside (so-called "cyclonucleosides"). ${ }^{[4]}$ In this respect, we have an interest in the synthesis and use of anomeric spironucleosides, whereby the anomeric carbon belongs to both the sugar moiety and the nucleobase (Figure 1). This fixes the nucleobase in a specific orientation around the $\mathrm{N}$-glycosidic bond, imposing an altered flexibility on the sugar moiety. Spiro-functionalised nucleosides have gained considerable interest with the discovery of (+)-hydantocidin (1), a natural spironucleoside with potent herbicidal and plant growth regulatory activity. ${ }^{[5]}$ However, to the best of our knowledge, synthetic work in this field is limited, with the majority of anomeric spirocycles being hydantoine or diketopiperazine analogues, or simple pseudonucleosides with anchored purinic and pyrimidinic bases. ${ }^{[6]}$

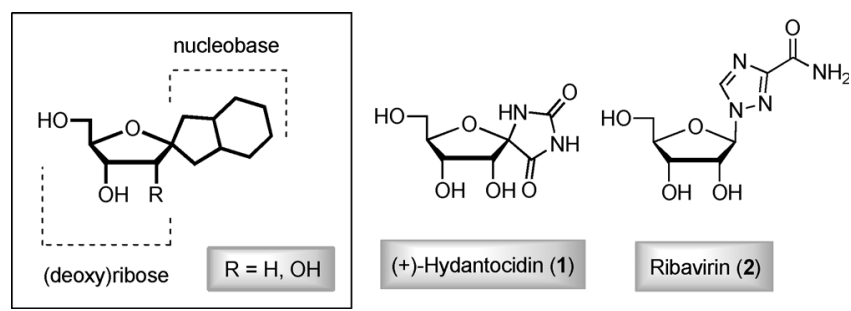

Figure 1. Representation of a spironucleoside (where the shared carbon is at the anomeric position), the spironucleoside hydantocidin, and the triazolyl antiviral ribavirin.

As part of an on-going programme within our laboratories on the synthesis of non-natural nucleic acids, ${ }^{[7]}$ we aimed to prepare a library of spiro-fuctionalised nucleosides, containing a [1,2,3]-triazolyl moiety using a straightforward and highly stereoselective route. It was felt that this class of spironucleoside would make an interesting alternative to the [1,2,4]-triazolyl class of nucleoside the biological activity of which is well known, owing to their resemblance to ribavirin $2 .{ }^{[8]}$ We therefore evaluated our resulting [1,2,3]-triazolospironucleosides for their anti-HMV (mouse hepatitis virus) activity in vitro.

As depicted in the retrosynthetic path (Scheme 1), the versatility of the synthetic strategy towards novel anomeric spironucleosides $\mathbf{3}$ lies in the strategic installation of azide and alkyne moieties on the D-psicofuranose derivative $\mathbf{4}$, followed by an intramolecular Huisgen 1,3-dipolar cycloaddition to generate the spirocyclic $[1,2,3]$-triazolooxazine ring. ${ }^{[9]}$ 


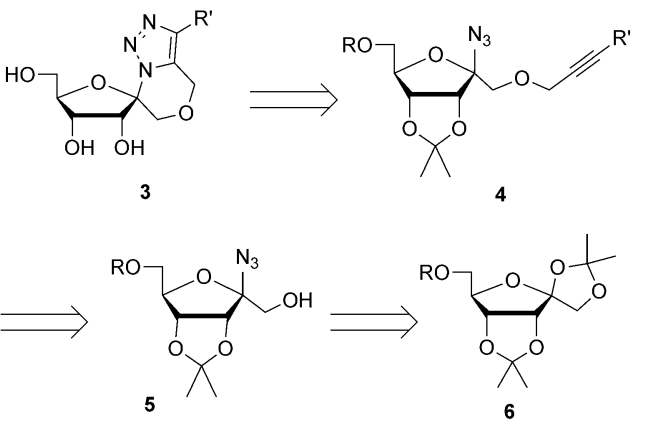

Scheme 1. Retrosynthetic access to [1,2,3]-spirotriazolooxazines.

The first part of the synthesis is shown in Scheme 2 and followed the general procedure described by Fuentes and coworkers. ${ }^{[10]}$ This involved isomerisation of 1,2:4,5-di-O-isopropylidene-D-psicopyranose (7; easily prepared in a multigram scale using a straightforward three-step procedure from $\beta$-D-fructopyranose) ${ }^{[11]}$ to its furanose form $\mathbf{6}$ a using amberlyst acid resin in acetone. The remaining alcohol was then converted to the benzoate ester $\mathbf{6} \mathbf{b}$ with a satisfactory overall yield of $70 \%$.
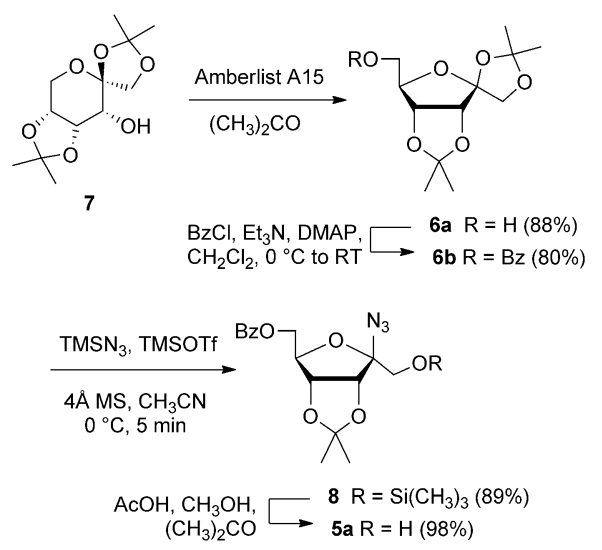

Scheme 2. Synthesis of the azido-ribose system.

The benzoate ester was then treated with azidotrimethylsilane in the presence of trimethylsilyl triflate in acetonitrile under stringently anhydrous conditions at $0{ }^{\circ} \mathrm{C}$ for $5 \mathrm{~min}$ to provide the $\beta$-azido-1-trimethylsilyl ether (8) as the sole anomer. The silyl group was then removed smoothly with a mixture of acetone, acetic acid and methanol, giving alcohol $\mathbf{5}$ a in $98 \%$ yield.

The alkylation of alcohol $\mathbf{5} \mathbf{a}$ with a range of propargyl bromides was then undertaken using BEMP (2-tert-butylimino-2-diethylamino-1,3-dimethylperhydro-1,3,2-diazaphosphorine) as base to give the crude propargylic ether intermediates. The 3arylprop-2-ynyl partners for the O-alkylation were prepared from commercially available aryl iodides and propargyl alcohol using a two-step process involving Sonogashira coupling ${ }^{[12]}$ followed by conversion of the resulting 3-arylprop-2-ynyl alcohols to their corresponding bromides under Appel conditions (see the Supporting Information). The crude propargyl ether inter-

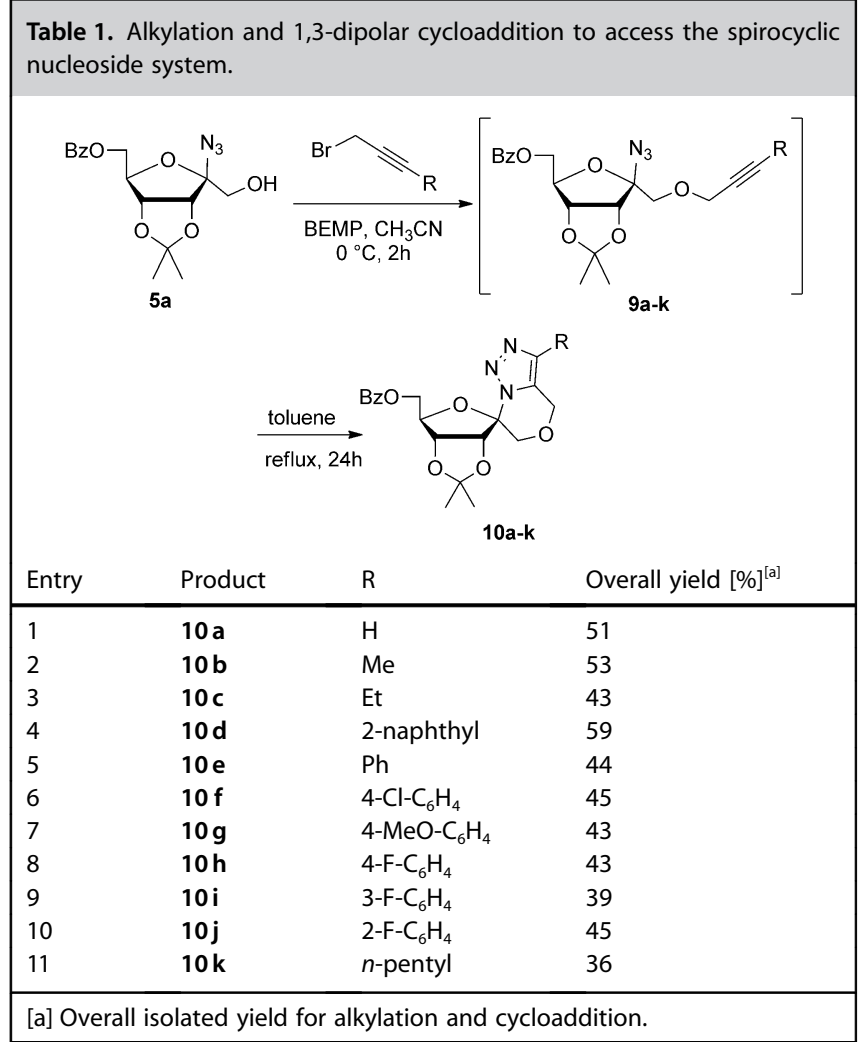

mediates 9 then underwent efficient intramolecular 1,3-dipolar cycloaddition upon heating in toluene for $24 \mathrm{~h}$ to give the novel protected anomeric spironucleoside library 10 (Table 1). ${ }^{[13]}$

Finally, deacylation of the spiroderivative 10 , using a $7 \mathrm{~N}$ solution of ammonia in methanol, followed by hydrolysis of the isopropylidene group with acidic resin (Dowex ${ }^{\circ} 50 \mathrm{~W}$ ) gave straightforward access to anomeric spironucleosides $\mathbf{3}$ in good yield (Scheme 3).

As proof of final structure and to gain an understanding of the conformation of these systems, an X-ray crystal structure of $\mathbf{3 g}$ was obtained from a thin $(0.02 \times 0.03 \times 0.31 \mathrm{~mm})$ single crystal (Figure 2). The structure in space group $P 2_{1}$ has two independent molecules in the asymmetric unit, each having a disordered benzene ring occupying two distinct conformations $\left(A\right.$ and $B$ ) at about $60^{\circ}$ different rotations about the aryl

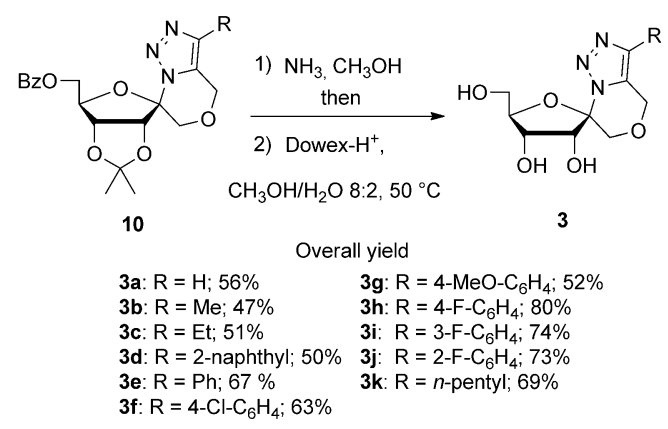

Scheme 3. Final deprotection steps to obtain novel anomeric spirocyclic system 3 . 


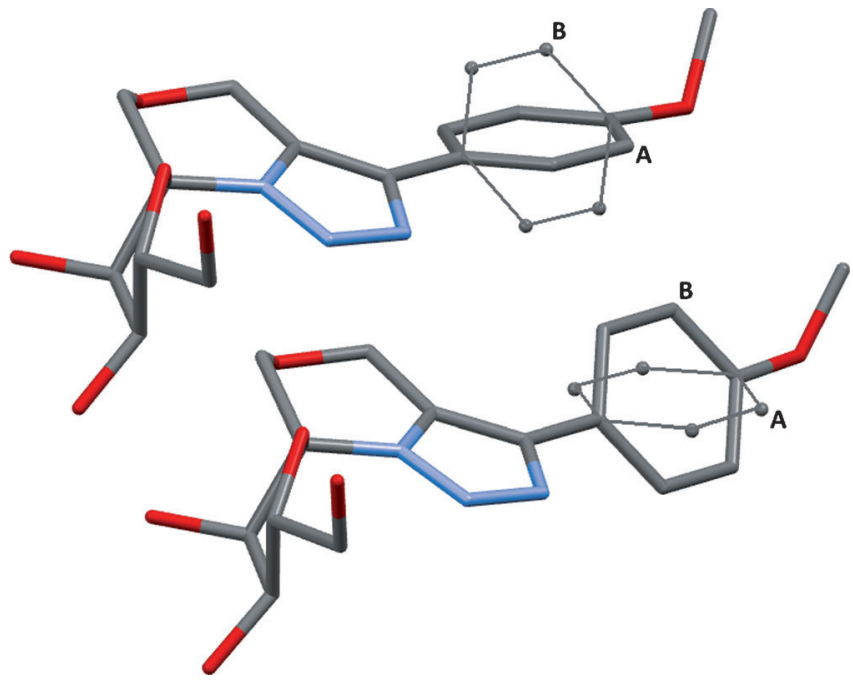

Figure 2. Crystal structure of spirocyclic nucleoside $\mathbf{3}$ g. CCDC-1003449 (3 g) contains the supplementary crystallographic data for this paper. These data can be obtained free of charge from The Cambridge Crystallographic Data Centre via www.ccdc.cam.ac.uk/data_request/cif.

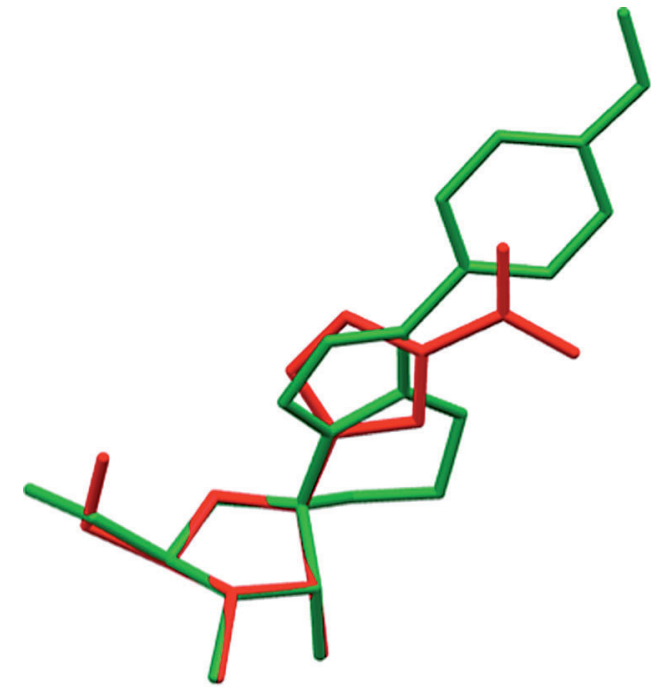

Figure 3. Overlay of $\mathbf{3} \mathbf{g}$ (green) with ribavirin (red), showing the similarities in conformation.

bond. In the upper molecule, conformation $A$ is $92 \%$ occupied and $B$ is $8 \%$ occupied, whilst in the lower molecule, the occupancies are reversed.

Encouragingly, and considering the "locked" nature of our nucleoside system, the crystal structure when overlaid with the $[1,2,4]$-triazolyl drug ribavirin showed remarkable similarities in conformation, particularly with respect to the ribose ring system (Figure 3). This prompted us to evaluate the antiviral activity of our nucleoside analogues and these studies are described below.

Coronaviruses are the largest and most complex RNA viruses known, encoding an unusually wide array of proteins that interact with or modify viral RNA. ${ }^{[14]}$ Examples include severe acute respiratory syndrome (SARS), and middle eastern respiratory syndrome (MERS), which are amongst the most lethal viruses currently known. Coronaviruses are predicted to be sensitive to RNA-like drugs, ${ }^{[15]}$ and some nucleosides, such as ribavirin, have anti-coronaviral activity. ${ }^{[16,17]}$ We therefore chose the model coronavirus MHV as a proving

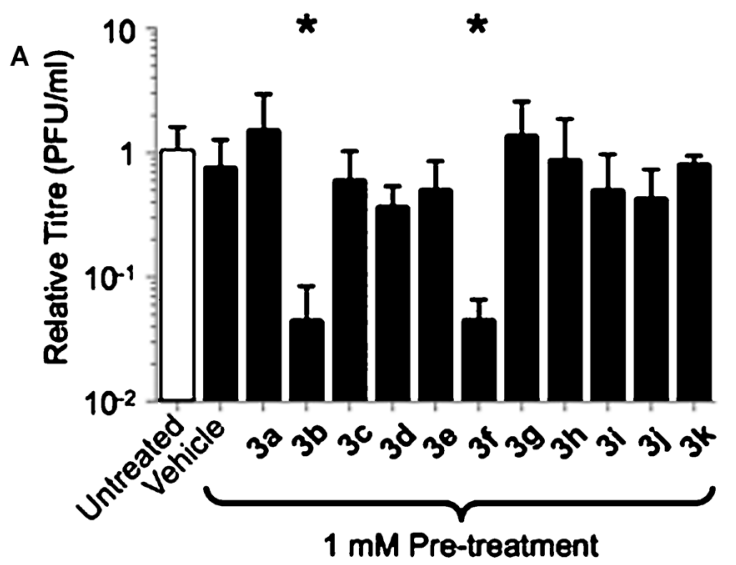

B
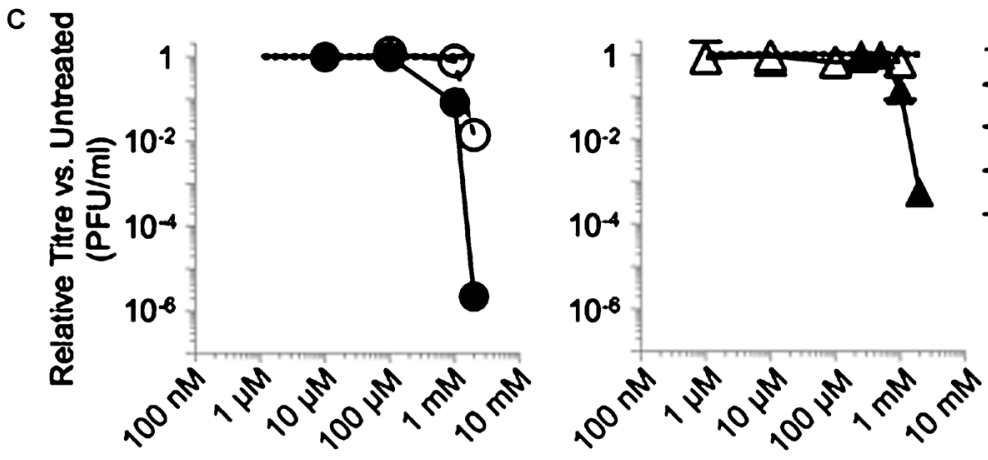

3h Pre-treatment + 14h Treatment

Figure 4. Antiviral effects of novel nucleosides. A) Cells were pre-treated with $1 \mathrm{~mm}$ compounds, DMSO-containing vehicle or mock treated $3 \mathrm{~h}$ before infection. Virus growth is shown relative to untreated controls. Compounds that reduced virus growth significantly $(P<0.5$ after unpaired t-test with Bonferroni correction) are indicated with stars. B) Reduction of cytopathic effects by $\mathbf{3} \mathbf{f}$. Infected cells were fixed, stained with crystal violet and adherent cells were imaged by light microscopy. The number of nuclei in single cell bodies and in virus-induced multinucleate syncytia was normalised to the number of nuclei present in uninfected, untreated controls (Uninfected). C) Experimental compounds were applied $3 \mathrm{~h}$ before addition of the virus, and were maintained throughout the experiment. Data points show the average virus titre \pm standard deviation based on 5-8 replicates. Virus growth was measured by plaque assay $14 \mathrm{~h}$ after inoculation.

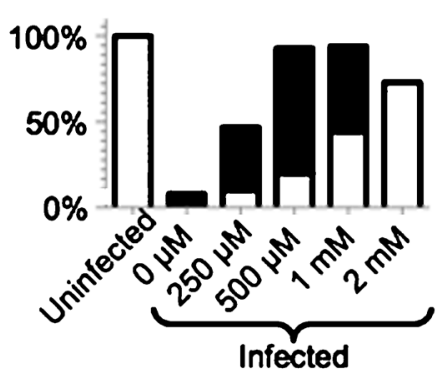


ground for the novel nucleoside analogues described in this study for antiviral activity.

In order to test for antiviral effects, MHV was grown on cells that had been pre-treated with the experimental compounds at a concentration of $1 \mathrm{~mm}$. The amount of MHV released from infected cells usually peaks at about $14 \mathrm{~h}$ after infection. Two of the treatments, $\mathbf{3} \mathbf{b}$ and $\mathbf{3} \mathbf{f}$ reduced the amount of $\mathrm{MHV}$ that was released by about tenfold (Figure $4 \mathrm{~A}$ ).

MHV infection in $17 \mathrm{Cl}-1$ cells normally results in formation of large multinucleate syncytia followed by detachment of cells from the culture flask. ${ }^{[18]}$ The most effective experimental compound from the previous assay was screened for the ability to protect cells from MHV-induced cytopathology. The $17 \mathrm{Cl}$ 1 cells were pre-treated with $3 \mathrm{f} 3 \mathrm{~h}$ before infection, and surviving cells were photographed $24 \mathrm{~h}$ after infection. Treatment with $\mathbf{3} \mathbf{f}$ resulted in a dose-dependent reduction in both syncytium formation and detachment (Figure 4B). From these data it was concluded that $\mathbf{3} \mathbf{f}$ exerted a protective effect on treated cells at concentrations up to $2 \mathrm{~mm}$. This also demonstrated that the apparent antiviral activity of $\mathbf{3} \mathbf{f}$ was not simply an artefact of cytotoxicity.

More detailed dose-response experiments were performed for four of the experimental compounds in order to better gauge their antiviral potential. Pre-treatment with $2 \mathrm{~mm}$ of $\mathbf{3} \mathbf{f}$ produced the strongest antiviral effects, resulting in approximately one million-fold reduction of MHV growth (Figure 4C). Together, these results demonstrate that $\mathbf{3} \mathbf{f}$ had antiviral activity against the model coronavirus MHV.

The $17 \mathrm{Cl}-1$ mouse lung fibroblast line supports high-titre MHV growth, and was therefore chosen for both toxicity and antiviral testing. The effects of treatment on cell viability were assessed by MTT assay. ${ }^{[19]}$ Cell viability was assessed after one day or three days. Of the compounds studied, the most promising were tested in this assay. Compound $\mathbf{3} \mathbf{d}$ was the most cytotoxic, while $\mathbf{3} \mathbf{b}, \mathbf{3} \mathbf{f}$ and $\mathbf{3} \mathbf{k}$ (included as a control) were better tolerated (Figure 5).

The concentration which produced a $50 \%$ reduction in cell viability in these assays was greater than $1 \mathrm{~mm}$ for each of the experimental compounds tested (Table 2), demonstrating that the compounds are relatively non-toxic.

\begin{tabular}{|c|c|c|c|c|}
\hline Entry & Nucleoside & $\begin{array}{l}E C_{50} \\
{[\mu \mathrm{M}]}\end{array}$ & $\begin{array}{l}\mathrm{CC}_{50} \\
{[\mu \mathrm{M}]}\end{array}$ & $\begin{array}{l}\text { Therapeutic } \\
\text { index }\end{array}$ \\
\hline 1 & $3 b$ & $410 \pm 50$ & $1510 \pm 90$ & 3.7 \\
\hline 2 & $3 d$ & $>2000$ & $1170 \pm 180$ & $<0.6$ \\
\hline 3 & $3 \mathrm{f}$ & $36 \pm 13$ & $>2000$ & $>56$ \\
\hline 4 & $3 \mathrm{k}$ & $1290 \pm 110$ & $>2000$ & $>1.6$ \\
\hline
\end{tabular}

A further experiment was performed in order to learn more about the mechanism of $\mathbf{3} \mathbf{f}$ antiviral activity by evolving drug resistance. MHV was serially passaged eight times on $17 \mathrm{Cl}$ 1 cells, which had been pre-treated with $1 \mathrm{~mm} \mathbf{3} \mathbf{f}$, a concentration that reproducibly reduced viral growth by about $90 \%$. Previous work on antiviral compounds suggested that these
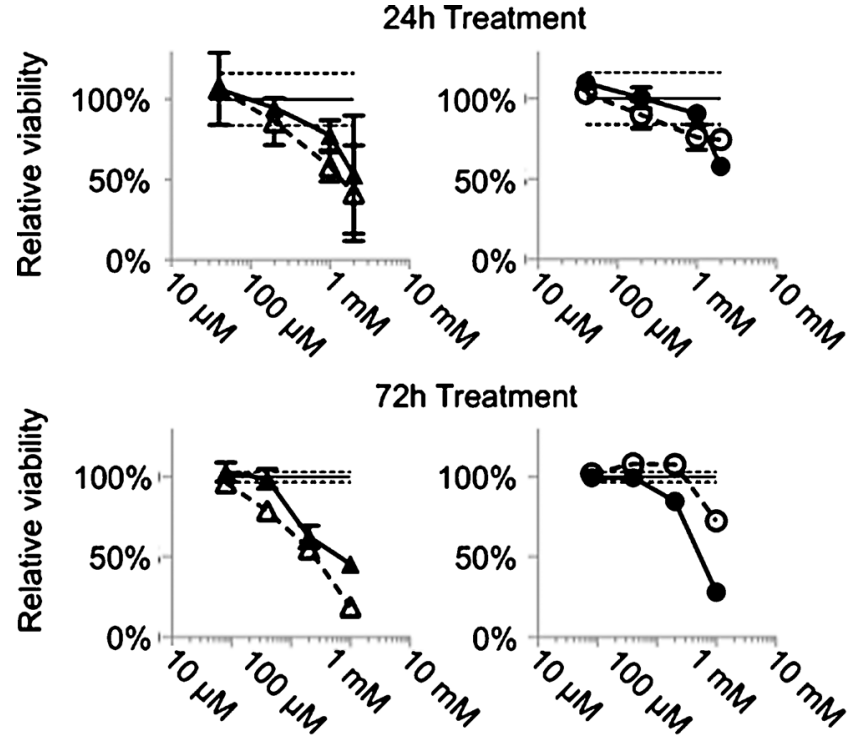

Figure 5. Dose-response effect of experimental compounds on cell viability. Effect of short ( $24 \mathrm{~h}$ ) and long (72 h) exposure to experimental compounds on cell viability. Experiments were performed in a mouse lung $17 \mathrm{Cl}-1$ fibroblast cell line that is highly permissive for MHV. Relative viability as measured by conversion of formazan to MTT is plotted against treatment dose for four representative compounds. Untreated: $\square ; \mathbf{3 b}$ : $\mathbf{\Delta} ; \mathbf{3} \mathbf{d}: \triangle ; \mathbf{3} \mathbf{f :} \bullet$; 3 k: $\bigcirc$.

conditions were appropriate for the selection of drug-resistant coronavirus within about five passages. ${ }^{[20]}$ However, MHV grown in the presence of $\mathbf{3} \mathbf{f}$ consistently produced about $10 \%$ of the virus produced in untreated control cells, and did not develop resistance (data not shown). These results suggest that the mechanism of action of $\mathbf{3} \mathbf{f}$ is unclear, and that effects of $\mathbf{3} \mathbf{f}$ on the cell cannot be ruled out as a potential explanation of the antiviral effects.

In conclusion, a novel triazolospirocylcic nucleoside array was assembled efficiently through intramolecular 1,3-dipolar cycloaddition methodology, and allowed the identification of agents that showed promising antiviral activity towards MHV - the most promising of these being the 4-chlorophenyl derivative $\mathbf{3} \mathbf{f}$. Further work is underway to establish the mechanism of action of this inhibitor.

\section{Acknowledgements}

The authors wish to acknowledge financial contributions from the University of Reading (to A.D.I. and H.M.N.A.-M.) and Syngenta (to A.D.I.), as well as Fraser White of Agilent Technologies for X-ray data collection and structure determination of $3 \mathrm{~g}$.

Keywords: alkynes • antiviral agents - cycloaddition nucleosides · spiro compounds

[1] a) L. P. Jordheim, D. Durantel, F. Zoulim, C. Dumontet, Nat. Rev. Drug Discovery $2013,12,447-464$. 
[2] For recent reviews, see : a) G. F. Deleavey, M. J. Damha, Chem. Biol. 2012, 19, 937-954; b) T. P. Prakash, Chem. Biodiversity 2011, 8, 1616 1641.

[3] For useful reviews, see : a) M. A. Campbell, J. Wengel, Chem. Soc. Rev. 2011, 40, 5680-5689; b) H. Kaur, B. R. Babu, S. Maiti, Chem. Rev. 2007 107, 4672-4697; c) L. Kværnø, J. Wengel, Chem. Commun. 2001, 14191424; d) J. K. Watts, Chem. Commun. 2013, 49, 5618-5620.

[4] For useful reviews, see: a) A. Mieczkowski, V. Roy, L. A. Agrofoglio, Chem. Rev. 2010, 110, 1828-1856; b) Y. Yoshimura, H. Takahata, Molecules 2012, 17, 11630-11654; c) A. J. A. Cobb, Org. Biomol. Chem. 2007, 5, 3260-3275.

[5] a) M. Nakajima, K. Itoi, Y. Tamamatsu, T. Kinoshita, T. Okasaki, K. Kawakubo, M. Shindou, T. Honma, M. Tohjigamori, T. Haneishi, J. Antibiot. 1991, 44, 293-300; b) R. Fonné-Pfister, P. Chemla, E. Ward, M. Girardet, K. E. Kreutz, R. B. Hozantko, H. J. Fromm, H.-P. Schär, M. Grütter, S. W. CowanJacob, Proc. Natl. Acad. Sci. USA 1996, 93, $9431-9436$.

[6] For a useful review, see: R. G. Soengas, S. Sandrina, Mini-Rev. Med. Chem. 2012, 12, 1485-1496 and references therein

[7] a) S. E. Fern, P. Heath, A. J. A. Cobb, Tetrahedron: Asymmetry 2011, 22, 149-152; b) G. Rangam, K. M. Schmitz, A. J. A. Cobb, S. K. PetersenMahrt, PLOS ONE 2012, 7, e43279.

[8] a) R. W. Sidwell, J. H. Huffman, G. P. Khare, L. B. Allen, J. T. Witkowski, R. K. Robins, Science 1972, 177, 705; b) S. Crotty, D. Maag, J. J. Arnold W. D. Zhong, J. Y. N. Lau, Z. Hong, R. Andino, C. E. Cameron, Nat. Med. 2000, 6, 1375-1379; c) L. Dudycz, D. Shugar, E. De Clercq, J. Descamps, J. Med. Chem. 1977, 20, 1354-1356; d) Y. Xia, F. Qu, L. Peng, Mini-Rev. Med. Chem. 2010, 10, 806-821. For recent examples of [1,2,3]-triazole analogues, see: e) M. L. G. Ferreira, L. C. S. Pinheiro, O. A. Santos-Filho M. D. S. Peçanha, C. Q. Sacramento, V. Machado, V. F. Ferreira, T. M. L Souza, N. Boechat, Med. Chem. Res. 2014, 24, 1501; f) T. Ostrowski, P. Januszcyk, M. Cieslak, J. Kazmierczak-Baranska, B. Nawrot, E. BartoszakAdamska, J. Ziedler, Bioorg. Med. Chem. 2011, 19, 4386-4398.
[9] a) R. Huisgen, Angew. Chem. 1963, 75, 604-637; b) R. Huisgen, R. Knorr L. Moebius, G. Szeimies, Chem. Ber. 1965, 98, 4014; c) R. Huisgen, G. Szeimies, L. Moebius, Chem. Ber. 1967, 100, 2494-2507. For a recent review of intramolecular "click" processes, see: d) K. C. Majumdar, K. Ray, Synthesis 2011, 3767-3783. For Cu'-catalysed syntheses in nucleic acid chemistry, see: e) F. Amblard, J. Hyun Cho, R. F. Schinazi, Chem. Rev. 2009, 109, 4207-4220.

[10] C. Gasch, M. A. Pradera, B. A. B. Salameh, J. L. Molina, J. Fuentes, Tetrahedron: Asymmetry 2001, 12, 1267-1277.

[11] R. Sridhar Perali, S. Mandava, R. Bandi, Tetrahedron 2011, 67, 4031 4035.

[12] K. Sonogashira, Y. Tohda, N. Hagihara, Tetrahedron Lett. 1975, 16, 4467 4470.

[13] R. Li, D. J. Jansen, A. Datta, Org. Biomol. Chem. 2009, 7, 1921-1930.

[14] B. W. Neuman, P. Chamberlain, F. Bowden, J. Joseph, Virus Res. 2013, DOI: 10.1016/j.virusres.2013.12.004.

[15] A. Azzi, S. X. Lin, Proteins Struct. Funct. Bioinf. 2004, 57, 12-14.

[16] E. L. Tan, E. E. Ooi, C. Y. Lin, H. C. Tan, A. E. Ling, B. Lim, L. W. Stanton, Emerging Infect. Dis. 2004, 10, $581-586$.

[17] D. L. Barnard, V. D. Hubbard, J. Burton, D. F. Smee, J. D. Marrey, M. J. Otto, R. W. Sidwell, Antiviral Chem. Chemother. 2004, 15, 15-22.

[18] T. Mosmann, J. Immunol. Methods 1983, 65, 55-63.

[19] R. Burrer, B. W. Neuman, J. P. Ting, D. A. Stein, H. M. Moulton, P. L. Iversen, P. Kuhn, M. J. Buchmeier, J. Virol. 2007, 81, 5637-5648.

[20] B. W. Neuman, D. A. Stein, A. D. Kroeker, M. J. Churchill, A. M. Kim, P. Kuhn, P. Dawson, H. M. Moulton, R. K. Bestwick, P. L. Iversen, M. J. Buchmeier, J. Virol. 2005, 79, 9665-9676.

Received: May 16, 2014

Published online on July 31, 2014 